Print ISSN: 2233-4165 / Online ISSN: 2233-5382 doi:http://dx.doi.org/10.13106/ijidb.2018.vol9.no5.7.

\title{
Study on the Undertaking Mode of High Tech Industry in Anhui Province : Based on the Perspective of Industrial Upgrading
}

\author{
Shao Mengmeng* \\ Received: March 17, 2018. Revised: March 30, 2018. Accepted: May 15, 2018.
}

\begin{abstract}
Purpose - The development of Anhui high-tech industry is the key to transforming the mode of economic development and optimizing the industrial structure.

Research design, data, and methodology - The data of paper that is the data of Anhui province and the six provinces of central China from 2010 to 2015, which analyzed the present situation of High-tech industry in Anhui Province by means of data comparison and literature analysis, and then explored several possible modes of undertaking.

Results - With the analysis of the current situation of the development of high-tech industry in Anhui Province, several possible modes for undertaking the transfer of high-tech industries in Anhui Province were explored: The mode of undertaking of Leading Enterprises + Industrial park, the mode of undertaking of differentiated development + Regional comprehensive exploitation and the mode of undertaking "Dynamic industrial Chain" + industrial cluster.

Conclusions - Based on the perspective of industrial upgrading, this paper analyzes the shortcomings of Anhui Province in the traditional mode of undertaking industrial transfer and expounds the inherent requirements of innovation industry undertaking. Finally, on the basis of the above analysis, the author explored three possible modes of acceptance.
\end{abstract}

Keywords: Anhui Province, High-Tech Industry, Mode of Undertaking.

JEL Classifications: L60, O11, R12.

\section{Introduction}

Industrial transfer has a significant impact on regional economic development. The effect of industrial transfer and its different modes are also different on economic development. The performance of unbalanced Chinese economic development is the level of economic development between the eastern and central western regions. Anhui Province, as one of the middle regions, has been undertaking the declining and non-competitive marginal industries from the eastern region for a long time, which makes Anhui province fall into the trap of "high growth and low development". Along with a new round of industrial transfer and its back to the Yangtze River Delta geography and policy advantages, Anhui Province gradually undertakes the transfer of high-tech industries for transform its economic development mode and optimize its industrial structure. However, Anhui Province undertake the transfer of high-tech

* College of Economics and Management, Nanjing University of Aeronautics and Astronautics, Nanjing, Jiangsu Province, China. Tel: +25-848-93190, E-mail: shaomm826@163.com industries showed the small-scale and crude passive mode. Therefore, not only the Anhui Province should also give full play to its autonomy and innovative undertaking model and build an industrial cluster, but also undertake high-tech industries from the eastern region with the advantage of cheap production factors. Anhui Province should attract high-tech Technology transfer industries, and step out of the industrial upgrading gradient trap to change the mode of economic development in Anhui Province.

Domestic and foreign scholars have a lot of research on industry undertaking theory. Foreign scholars Sammarrat and Belussi (2006) pointed out that in the process of industrial transfer, enterprises tend to transfer with their related supporting enterprises; Klmienko (2003) believes that the joint transfer of related enterprises is conducive to the formation of industrial clusters, followed by clusters that emit a powerful "magnetic force", which attract more enterprises to move to the area and make the industrial clusters grow larger and larger ; Hwang (2003) concludes that the key to its success by studying the Korean electronics industry's investment in the EU lies in the fact that South Korea uses a cluster of investments centered on its own leading firms 
rather than small-scale decentralized investments. Domestic scholar Guo and Zou (2015) discussed that the leading enterprises undertake industrial transfer led the industrial cluster transfer model, the industrial chain type undertake the industrial transfer model, the cross-regional collaborative innovation model and the internal spatial differentiation acceptance model in Chengyu Economic Zone from the perspective of industrial upgrading and spatial equilibrium; Zhu and Zou (2013) first analyzed the current situation of undertaking the industrial transfer in eastern China from 2000 to 2011 in China, and then analyzed the internal mechanism of the major modes of industrial transfer; Liu and $\mathrm{Li}$ (2013) believes that in undertaking the process of industrial transfer, Jiangxi should adhere to the strategy of environmental protection and sustainable development, which use system management theory to manage the industrial transfer environment. Jiangxi strictly control the approval of enterprises for land use and strictly implement the access standards, which focus on strengthening the strategy of industrial clusters and establish an effective mechanism for accelerating the transformation of economic development methods; Zhao (2017) used Zhangjiakou as a support point for the Beijing-Tianjin-Hebei integrated region, making it a processing base for transforming high-tech and industrial products in Beijing and Tianjin. Zhangjiakou takes advantage of attracting the transfer of high-tech industries related to Beijing and Tianjin, thus promoting the adjustment and optimization of industrial structure and forming a new type of green industry center city for sustainable development. Although the above research explores the mode of undertaking industrial transfer from different angles, it remains to be argued whether undertaking the mode of industrial transfer is suitable for the development of high-tech industries in the middle of Anhui Province.

Based on the perspective of industrial upgrading, this paper starts from the shortage of traditional undertaking industrial transfer model in Anhui Province, then analyzes the internal requirement of innovation industry undertaking model, and in combination with the present situation of High-tech industry in Anhui Province, explores several innovative models of undertaking industrial transfer of High-tech industry in Anhui Province. Represented by Anhui Province significance, it hopes to draw some lessons for undertaking high-tech industries transfer in middle provinces and underdeveloped areas.

\section{The Shortage of Traditional Undertaking Industrial Transfer Mode in Anhui Province}

In Anhui Province, The traditional pattern of undertaking industrial transfer is a non-technical innovation core and simply conducts a partial or single industrial transfer.

This model mainly utilizes the cheap land, labor resources and cost advantages of Anhui Province to carries on the passive undertaking of resource type, scale type and cost type for any transfer from domestic and foreign industries are not rejected. According to the theory of comparative advantage, Anhui Province undertaken advantageous industries and stimulated the productivity of the region. However, this is also a potential dependence on the industrial transfer in the eastern region, and causes forming a solidified mode of undertaking. After long-term development, economic development conditions have changed in Anhui Province. If it continues following the traditional undertaking will result in excessive inheritance of traditional industries in Anhui Province and lack of innovation so that the industrial chain will always be in a low value-added state. It result in the economy being in a dilemma of high growth and low development, and ultimately make the industrial structure rigid.

\section{The Internal Requirement of Innovation Industry Undertaking Mode under the Perspective of Industrial Upgrading}

The traditional mode of undertaking industrial transfer is a model with low technical content, high pollution and high energy consumption. In the short term, it will promote the economic development in the region. However, in the long run, it will trap the regional economy in the gradient of industrial upgrading and be detrimental to the sustainable economic development. This paper expounds the insufficiency of the traditional mode of undertaking industrial transfer. The way that undertake industrial transfer should be to break through the following directions from the perspective of industrial upgrading in Anhui Province.

\subsection{The requirements of cluster undertaking and industrial structure upgrading}

At present, the trend of "hug-style" and industrial-chain transfer is becoming increasingly clear in the eastern enterprises part of China. Anhui Province should seize this opportunity, which actively import and play to the leading role of leading enterprises to promote the overall and industrial chain transfer of related industries and supporting industries and promote the transfer of industry to an orderly space concentration transformation for enhancing competitiveness. Furthermore, Anhui Province should follow the pattern of industrial transfer toward advanced, ecological and innovative development. It is not only pursuing the improvement of economic output but also improving the high-tech industrial chain, promoting innovation ability and upgrading industrial structure in Anhui Province. 


\subsection{The requirements of Proactive undertaking and innovative undertaking}

In the past, most of the industries which were those with low technical and backwardness eliminated in the eastern region undertaken by Anhui Province. It has formed a potential dependency relationship with eastern region and led to undertaking the eastern area industry transfer passively. Anhui Province should take the innovation as its core and pillar to undertake industrial transfer. It should give full play to its subjective initiative, and attract investment actively and promote the combination of industry, education and research. Anhui Province should pay more attention to industrial technology and industrial talents, especially the overall undertaking of $R \& D$ centers. It will focus on undertaking the enterprises that are independent innovation, science and technology innovation settled in Anhui Province.

\subsection{The requirements of Green undertaking and environmental protection}

To undertake the industrial transfer, Anhui Province can neither over-consume resources to promote economic development and stimulate export, nor at the expense of the ecological environment, and must uphold the green undertaking and scientific development. Under the dual constraints of resources and environment, Anhui Province must change the traditional mode of undertaking industrial transfer. Under the premise of green undertaking, innovation should continue to be the core. For projects that are banned by the State, projects with high pollution and high energy consumption, it will never be imported. Anhui Province should explore the mode of undertaking industrial transfer that maximizes the overall benefits of industrial transfer for achieving sustainable development.

\section{Development Status of High-Tech Industry in Anhui Province}

In 2016, the output value of high-tech industries that are above designated size in Anhui Province reached 1.82196 trillion Yuan, which have an increase of $19.0 \%$ over the previous year and $10 \%$ higher than the growth rate of the above-scale enterprises. The added value of high-tech industries that are above designated size in Anhui Province was 409.49 billion Yuan, which have an increase of $11.3 \%$ over the previous year and 2 percentage points higher than the provincial GDP growth rate. It demonstrates the steady development of high-tech industries in Anhui Province.

\subsection{Increasing investment in human and financial resources for high-tech industries}

As can be seen from <Table 1>, Anhui Province's R \& D expenditure in 2015 was 2.6 times that of 2010, which shows an increasing trend. However, the share of $R \& D$ expenditure in GDP remains low at $1 \%-2 \%$. Although both government revenue and government funding are growing, the share of government funding in fiscal expenditure has remained low. Therefore, the government should increase investment in scientific and technological innovation, and expand channels of funding for private enterprises.

It can be seen from <Table $2>$ that in the six years from 2010 to 2015, the R \& D personnel in 2015 are twice that of 2010. In the past six years, the total number of scientific and technological personnel has been increasing year by year in Anhui Province. The number of postgraduate students has also risen steadily in the university. However, the growth rate of $R$ \& D personnel declined in 2015, leading to a decrease in technological innovation and a decrease in the number of patents and dissertations, which will affect the development of hi-tech industries adversely.

<Table 1> 2010-2015 Science and Technology Funds in Anhui Province

\begin{tabular}{|c|c|c|c|c|c|c|}
\hline Year & 2010 & 2011 & 2012 & 2013 & 2014 & 2015 \\
\hline$R$ \& $D$ funding (billion) & 163.72 & 214.64 & 281.8 & 352.1 & 393.6 & 431.75 \\
\hline$R$ \& $D$ expenditure as a share of GDP (\%) & 1.32 & 1.40 & 1.64 & 1.83 & 1.89 & 1.96 \\
\hline Government appropriation as a proportion of fiscal expenditure (\%) & 1.91 & 2.05 & 2.35 & 2.52 & 2.78 & 2.82 \\
\hline Government funding (billion) & 58.01 & 76.81 & 96.47 & 109.7 & 129.6 & 147.9 \\
\hline
\end{tabular}

<Table 2> 2010-2015 Science and technology human resources in Anhui Province

\begin{tabular}{|c|c|c|c|c|c|c|}
\hline Year & 2010 & 2011 & 2012 & 2013 & 2014 & 2015 \\
\hline Scientific and technical personnel (million people) & 23.65 & 26.78 & 30.52 & 33.91 & 36.51 & 35.98 \\
\hline R \& D staff (million people) & 9.00 & 12.00 & 15.63 & 18.06 & 20.10 & 21.30 \\
\hline$R \& D$ equivalent to full-time equivalent (million people/years) & 6.42 & 8.10 & 10.30 & 11.93 & 12.93 & 13.36 \\
\hline Number of postgraduate students in the school (million people) & 3.90 & 4.17 & 4.43 & 4.65 & 4.66 & 5.20 \\
\hline
\end{tabular}


Through the investment of human and financial resources of high-tech industry in Anhui Province, it show that the investment shows a trend of increasing year by year in human and financial resources. This shows that Anhui Province attaches importance to scientific and technological innovation, and strives to promote the development of high-tech industries. In the eastern region, Anhui Province has provided the talent and policy basis for taking the initiative in undertaking the transfer of high-tech industries and has created a good atmosphere of scientific and technological innovation.

\subsection{Although high-tech industries started late in Anhui Province, the output of scientific and technological innovations increased rapidly.}

The output of technological innovation is based on the output value of enterprises above the scale of hi-tech industries, the turnover of contracts in the technology market, the number of patents granted and the number of scientific papers published in Chinese periodicals. Scientific and technological innovation output is a key indicator that weighed the level of scientific and technological innovation and the capability of science and technology innovation.

It can be seen from Tables 3 and 4 that in 2015, 127709 patent applications were accepted, which ranked 6th in the country and 1 in the middle. The number of patents was granted 59039, which ranked the 7th in the country and ranked No. 1 in the middle. It indicated that the number of scientific and technological achievements multiplied every year. In addition, the number of patent applications has increased rapidly since 2010 in Anhui, and the number of patent grants in 2015 was 3.6 times of that in 2010, and it indicated that the output of technological innovation has been growing rapidly in hi-tech industries. Finally, it is important that the proportion of the added value of high-tech industries in GDP is getting higher and higher, and reached $30.4 \%$ unexpectedly in 2015 . It indicated that the development of high-tech industries is the key to sustainable economic development and upgrading of industrial structure.

Relatively, Anhui's high-tech industry started late. Although the output of technological innovation has been growing rapidly and has been developing rapidly in the central region, the gap is still large compared with the eastern region. Therefore, when strengthening its own scientific and technological innovation, Anhui Province has also transformed and innovated the mode of industry undertaking. It will step up efforts to introduce talented people from the eastern region and take the initiative to undertake emerging high-tech leading industries to boost the development of local high-tech industries.

\subsection{The improvement of enterprise innovation ability and the new development of Platform drive}

Enterprise scientific and technological personnel, enterprise R\&D investment and patent applications are the basis for technological innovation capability, which determine the level of development of high-tech industries in the region, the science and technology personnel and $R$ \& $D$ expenditures to a large extent. And patent applications increased by $52 \%$, $163.71 \%$ and $238.03 \%$ respectively in the six years $(<$ Table 1$\rangle$,

<Table 3> 2010-2015 science and technology output in Anhui Province

\begin{tabular}{|c|c|c|c|c|c|c|}
\hline Year & 2010 & 2011 & 2012 & 2013 & 2014 & 2015 \\
\hline Patent application acceptance (pieces) & 37780 & 48556 & 74888 & 93353 & 99160 & 127709 \\
\hline Million population patent acceptance (pieces) & 5.53 & 7.06 & 10.85 & 13.47 & 14.30 & 18.37 \\
\hline Patent application authorization (pieces) & 16012 & 32681 & 43321 & 48849 & 48380 & 59039 \\
\hline Million population patent authorization (pieces) & 2.35 & 4.75 & 6.28 & 7.05 & 6.98 & 8.50 \\
\hline Domestic Chinese Journal of Science Papers (articles) & 39668 & 43811 & 46625 & 50448 & 51706 & 52433 \\
\hline High-tech industry output value (billion) & 5968 & 8330 & 10255 & 12053 & 13526 & 15314 \\
\hline The proportion of high-tech industry added value to GDP (\%) & 13.2 & 14.2 & 15.2 & 15.8 & 16.1 & 30.4 \\
\hline
\end{tabular}

<Table 4> Comparison of main innovation indexes of six provinces in the middle of 2015

\begin{tabular}{|c|c|c|c|c|c|c|c|}
\hline Index & Anhui & Hubei & Hunan & Henan & Shanxi & Jiangxi & $\begin{array}{c}\text { Anhui's ranking } \\
\text { in the country }\end{array}$ \\
\hline R\&D funds (billion) & 431.75 & 561.74 & 412.67 & 435.04 & 132.53 & 173.18 & 11 \\
\hline Accounting for the proportion of GDP (\%) & 1.96 & 1.90 & 1.43 & 1.18 & 1.04 & 1.04 & 9 \\
\hline Funding for local financial science and technology (billion) & 147.94 & 157.36 & 66.00 & 83.25 & 37.47 & 74.79 & 8 \\
\hline Proportion of local fiscal expenditure (\%) & 2.82 & 2.57 & 1.16 & 1.22 & 1.09 & 1.69 & 7 \\
\hline Invention patent application amount (item) & 68314 & 30204 & 19499 & 21338 & 5680 & 5722 & 5 \\
\hline Invention patent authorized amount (item) & 11180 & 7766 & 6776 & 5384 & 2432 & 1639 & 7 \\
\hline
\end{tabular}


<Table 5> 2010-2015 Science and technology facilities in Anhui Province

\begin{tabular}{|c|c|c|c|c|c|c|}
\hline Year & 2010 & 2011 & 2012 & 2013 & 2014 & 2015 \\
\hline R\&D organization & 2221 & 2091 & 3013 & 3484 & 4093 & 4817 \\
\hline Technology business incubator & 51 & 60 & 70 & 70 & 85 & 96 \\
\hline Productivity Promotion Center & 58 & 86 & 107 & 117 & 127 & 129 \\
\hline Technical Center for enterprises above the provincial level & 453 & 535 & 616 & 717 & 832 & 931 \\
\hline Engineering (technical) Research Center above the provincial level & 205 & 277 & 343 & 412 & 487 & 557 \\
\hline Provincial (including key) laboratories & 92 & 99 & 105 & 111 & 111 & 106 \\
\hline
\end{tabular}

$<$ Table $3>$, and $<$ Table $4>$ ). From $<$ Table $5>$ that in the past six years, the number of scientific and technological institutions has increased overall trend in Anhui Province. In 2015 , the number of $R \& D$ institutions has doubled that of 2010. However, the number of provincial key laboratories has not increased but decreased in 2015. The decrease is harm to the development of science and technology innovation in the number of science and technology institutions. We should increase capital investment to create more research and innovation platforms. In 2015, the number of science and technology innovation intermediaries steadily increased in Anhui Province, there were 2.594 million square meters of hatching establishments in 96 science and technology business incubators in Anhui Province, with 3032 incubated enterprises with an annual operating income of 9.48 billion Yuan.

The year-by-year growth of science and technology innovation platform, which has led to the continuous increase of output of science and technology innovation in Anhui Province, and promoted the development of local high-tech industries, and enhanced the transfer of high-tech industries in the eastern region. It has provided infrastructure and supporting facilities for undertaking the transfer of high-tech industries in the eastern region, and reduced transaction costs and made it possible to transfer high-tech industries in the eastern region.

\section{The Innovation of Undertaking Mode for Undertaking the Transfer of High-Tech Industries in Anhui Province}

From the above development of High-tech industry in Anhui Province, we can see that Anhui Province has well developed for its infrastructural facilities and personnel training and has provided a favorable environmental basis for undertaking the transfer of high-tech industries. In recent years, the steady development of high-tech industries in Anhui Province has a great connection with the mode of undertaking the conversion and taking the initiative to undertake the transfer of high-tech industries from the eastern region. Therefore, Anhui Province seek for the "Anhui characteristics" of the flexible mode of undertaking actively and can explore the innovation of undertaking mode for undertaking the transfer of high-tech industries in Anhui Province from the following aspects.

\subsection{Leading Enterprises + Industrial park to promote the mode of undertaking}

Leading enterprises promote industrial cluster transfer, which refer to the introduction of a leading enterprise in a certain field, and make the related industries and supporting enterprises transfer together, finally form an industrial cluster effect of an industrial undertaking mode.

Leading enterprises will play a positive external role in infrastructure construction, knowledge innovation and overflow, brand marketing and reputation maintenance, etc., by reducing the transaction costs of various links. It drive the development of other related industries, and promote the formation of industrial clusters and structural upgrading and the formation of industrial parks. Small and medium-sized enterprises depend on the development of leading enterprises in the cluster, relevant supporting enterprises provide relevant supporting products for the leading enterprises, thus forming a compact cluster system with the leading enterprises as the core. Once the leading enterprises issue a signal of strategic adjustment, other dependent enterprises will make corresponding strategic adjustments to meet the requirements of the leading enterprises. Therefore, when the factor costs and policy conditions of the location where the leading enterprises are located change, they will choose to move to other regions in order to maximize their profits, so that the relevant supporting enterprises will also be collectively transferred as a cluster.

To undertake the overall transfer of leading enterprises, the place where undertake the transfer of industries will quickly form an industrial cluster, and change the industrial structure, and promote the development of local small and medium enterprises. The specific path is as follows: First, it can undertake a strongly related and supporting industries, and focus on the introduction of science and technology innovation ability and a wide range of radiation leading enterprises; Second, it can strengthen the development of local leading enterprises, and play a leading role in the formation of small and medium-sized enterprises radiation role, and broaden the industrial chain; Thirdly, it should 
strengthen local infrastructure construction and improve supporting capacity so that foreign leading enterprises can purchase nearby, strengthen cooperation and reduce transaction costs.

The industrial cluster of Hefei high-tech zone is a typical industrial cluster formed by the industrial transfer of leading enterprises in Anhui Province. At present, the leading enterprises have formed a number of agglomeration areas or clusters in Hefei high-tech zone around the leading industries, such as the Change sedan, micro-business vehicles as the leading, digital automotive instrumentation for the technical representative of the automobile and its parts and components of the automotive industry agglomeration. With Midea, Rongshida Sanyo, Gree as the representative of household electrical appliances industry agglomeration. With a group of backbone software enterprises such as IFLYTEK, the software industry cluster based on Hefei Software Park. With the Xiangyang Technology Co., Ltd. of Anhui Province, CLP Group, Anhui Allianz Group, Anhui Heter Microwave Communications Co., Ltd. as the backbone of the traditional electronics and information industry agglomeration. The industrial agglomeration of gene drugs and proprietary Chinese medicine products based on bio-engineering group and Golden Continental Biopharmaceutical Co., Ltd; Hefei Cube Pharmaceutical Co., Ltd. as the leading enterprises of biological extraction of pharmaceutical industry cluster. Anhui Guofeng Plastic Co., Ltd. as the leading enterprise of plastic products industry gathering and so on. At the same time, the cluster is equipped with corresponding universities, domestic and foreign $R \& D$ institutions and incubators, and a large number of senior management experts, technical personnel and investors entered the group, which showing a strong ability to gather.

\subsection{Differentiated development + Regional comprehensive exploitation of the mode of undertaking}

The industrial cluster the mode of undertaking for High-tech leading enterprises has driven the whole transfer of industry, which makes the whole development of local related industries and ancillary industries, and lowers the internal transaction cost of the High-tech leading enterprises and promotes the sustainable development of the economy, which is based on good scientific and technological innovation locally. However, the economic and technological development levels of various cities in Anhui Province are not balanced. This model is not conducive to the development of local science and technology with a low level of science and technology. In areas with a low level of science and technology, it does not form the basis and conditions for scientific and technological innovation, which is not conducive to the development of high-tech industries. Therefore, in this case, Anhui Province can seek the development of differentiation and the mode of regional comprehensive exploitation.

The mode of carrying out the differential development and regional comprehensive exploitation in Anhui Province, which seek the pattern of regional characteristics and differentiated development under the different development stage, development demand and strategic orientation of each city. Anhui Province plans to cultivate the Wanjiang City Belt, and the Wanjiang City Belt will effectively support the formation of a space pattern with close space and close economic ties in Anhui Province. Anhui Province should explore the mode of carrying forward the differentiated and coordinated development of the carrier of the economic belt.

The Wanjiang City Belt develops the industrial chain extension mode and the High-tech industrial park pattern. The Wanjiang City Belt takes the Yangtze River as the "development axis", Hefei and Wuhu as "dual-core", Chuzhou and Xuancheng as "two wings" of "two-axis dual-core" industrial layout, which will further strengthen the competitive industries such as automobiles, metallurgy, chemicals and household appliances, and foster high-tech industries such as electronic information, biology and public safety. The combination of manufacturing and high-tech industries enables the outsourcing of auto parts into on-site auto assembly and the formation of a car industry chain for the production of auto parts - fine processing - assembly marketing logistics. Wanjiang City Belt is located in the lower reaches of the Yangtze River and has a relatively weak resource and environmental carrying capacity. It insists on combining green undertaking with environmental protection, scientifically planning industrial parks and functional positioning, and aiming at technological innovation and cleaner production, attracting eco-friendly projects, and undertake the green new energy sources, new materials and other high-tech industries.

\section{3. "Dynamic Industrial Chain" + Industrial Cluster Mode of Undertaking}

The differentiated development and the mode of undertaking regional comprehensive development can realize the coordinated development of various regions, the optimal allocation of resources and effective competition. The model that achieve comprehensive and coordinated development of the region, but it does not refine the industrial chain, and did not achieve the dynamic development of the industrial chain.

The "Dynamic industrial Chain" mode of undertaking refers to taking the industrial chain as the basis, and taking the weak industrial chain and the extended industrial chain as the targets and motivated undertaking the transfer of enterprises to form a dynamic industrial chain - the mode of undertaking industrial clusters. This model is suitable for administrative regions or economic zones especially. The administrative area has vast land area, which has complete 
infrastructure and complete industrial chain and prototype of industrial cluster. However, the administrative regions can introduce the target industries through their own capabilities under the weakness of the industrial chain and so as to upgrade the industrial structure and improve the industrial efficiency.

The way that build and strengthen the industrial chain is different in different regions. First: a relatively complete industrial chain, which has the resources, personnel and other advantages, but the outward expansion and vertical contact is weak for enterprise in Anhui Province. Such industrial chain should attach importance to undertake high-tech industries, develop core technologies and nurture knowledge-based talents, and strengthen vertical contact. Second, for the industrial chain that is incomplete and missing from the key links, leading enterprises should be introduced at key links. Thirdly, a complete industrial chain cannot be formed for the lone-loop region where only part of the industrial chain cannot be formed. On the basis of strengthening its own advantages, it should expand outward to introduce vacancies in the regional industrial chain as a whole and develop advantageous industries.

The automobile and auto parts industry is the typical of industrial chain-type undertaking industry transfer in Wuhu. It has a more complete industrial chain, which build own brand at the same time and undertake a core technology of high-tech industries, it should attach importance to the optimization and upgrade of the automobile industry during the industry undertaking, and exert the local automobile leading enterprise to drive the whole transfer of industry, and form industrial cluster-industrial park. Wuhu auto parts rapid growth in production capacity, which undertake a number of well-known domestic and foreign auto parts enterprises Continental AG, Italy Fiat, the United States Johnson, the United States Delphi, the United States Cooper, the United States ASIMCO, South Korea POSCO, Sweden SKF and other well-known investment in the development of regional investment. At present, there are totally over 100 auto parts manufacturers in the zone, including more than 50 enterprises above designated size. The products cover various systems of auto parts and components. Chery Automobile, an independent brand of Wuhu City, which has formed an annual production capacity of 1 million engines and 900,000 vehicles. Chery Group sold a total of 550,100 units in 2015 , an increase of $8.3 \%$; one of the domestic sales of 464,000 units, an increase of $15.7 \%$, the increase exceeded the overall sales growth rate of domestic passenger cars $8.4 \%$, which achieve the export of 87,000 vehicles and ranked first in the domestic automobile enterprises for 13 consecutive years.

The formation of upstream, midstream and downstream industries is an important symbol of the industrial chain. Nowadays the industrial chain of the four major industrial clusters High-tech Zone has been initially formed in Hefei. For example, there are more than 300 enterprises in the electromechanical industrial chain in the electromechanical integration cluster and more than 100 enterprises in the new material cluster in the industrial chain of plastic products. Among them, leading enterprises are mostly mid-stream production-oriented enterprises. The supply, production and R\&D capabilities of upstream enterprises are recognized by the leading enterprises and the downstream enterprises basically ensure the smooth sales channels. Knowledge and technology are mainly held in the hands of leading enterprises. For example, IFLYTEK is an upstream enterprise and a technology provider as a leading enterprise in the electronic information industry cluster. More than 500 mid-stream and downstream enterprises are located in more than 20 different industries across the country.

Based on the existing industries in Anhui Province, it will introduce the chain-related industries and drive the upstream and downstream industries that support them to form a "Dynamic industrial Chain" development - industrial clusters. If the undertaking land a certain basis for industrial clusters, but part of the industrial chain development is weak, the undertaking land should be targeted to introduce weak links industries, and the formation of the industrial chain, and the formation of industrial clusters. If the undertaking place cannot build a complete industrial chain, it should embed the entire industry to undertake the transfer of industries be based on its own basic conditions. According to the existing industrial foundation of Anhui Province, which focus on the lack of related enterprises with weak industrial chain, the paper focuses on "strong chain" work on the three major industries of electronic information and advanced equipment manufacturing and deep processing in Anhui Province.

\section{Discussion}

\subsection{Accelerating the upgrade of industrial structure}

Based on the present situation of High-tech industry development in Anhui Province, this paper probes into three kinds of High-tech industry undertaking mode. First of all, the undertaking model of leading enterprises + industrial parks is carried out under the premise of relatively complete local infrastructure, and a good atmosphere of innovation has provided convenience for the transfer of leading enterprises and reduced costs. The leading role of the leading enterprises is conducive to the formation of an industrial park, which in turn creates a clustering and linkage effect, it drives the transformation of the industrial structure of the entire region and accelerates the development of the local economy. For differentiated development + regional comprehensive development undertaking model is based on the differences in the level of economic development of various cities in Anhui Province. In the premise of differentiated development, it will promote the integrated 
development of the internal, bearing and bearing grounds, and the grounding and transfer of the ground. And it can promote optimal allocation of resources and effective competition, and promote the comprehensive transformation of the industrial structure of the entire region of Anhui Province. The "Dynamic industrial Chain" + industrial cluster undertaking model is proposed in terms of the integrity of the industry chain. In Anhui Province, only a few prefecture-level cities have complete industrial chains, and the industrial chain is relatively weak in most cities. Therefore, it is necessary to undertake different chain-deficient enterprises for different regions, which form a complete industrial chain and then drive the dynamic development of the industrial chain. So as to achieve the mutual supporting development and industrial clustering of various industrial chains.

Anhui Province has invested heavily in scientific and technological funds and personnel, which improve the infrastructure and platforms for the development of high-tech industries. In order to undertake the Yangtze River Delta and international industrial transfer, it lays a foundation for the soft and hard environment. However, the development of high-tech industries still suffers from problems such as low innovation efficiency and outdated acceptance model in Anhui. Therefore, on the basis of the literature analysis, this paper innovates the pattern of undertaking high-tech industries. It has important practical significance for driving Anhui Province out of industrial upgrading and accelerating the upgrading of industrial structure.

\subsection{Promoting economic sustainable development}

Environment is an important prerequisite for development and must be guided by the theory of sustainable development. In combination with the characteristics of regional environmental economy, which will innovate the pattern of industrial acceptance and achieve "win-win" economic development and ecological environmental protection. In the past, Anhui Province passively accepted point- and bulk-scale industrial transfers for rapid economic development. Most of them are low-end industries with high pollution and high energy consumption. They cannot drive sustained economic development and increase environmental costs. If Anhui Province wants to shift the gradient trap across industries, it must change the pattern of undertaking industries and selective initiative undertake the transfer of emerging high-tech industries. Only by fundamentally changing the economic development mode and industrial structure of Anhui Province, can it be developed in the direction of environmental protection and economic sustainability.

\section{Conclusion}

At first, this paper analyzes the shortcomings of the traditional mode of undertaking industrial transfer in Anhui Province, and points out that if Anhui Province wants to achieve sustainable economic development. It must change its mode of undertaking industrial transfer. Anhui Province should undertake high-tech industries that promote the upgrading of the industrial structure and develop in the direction of green undertaking, innovation undertaking and cluster undertaking. Then on the basis of the data of 2010-2015, this paper analyzes the status quo of the undertaking of high-tech industries in Anhui Province, and finally explores the mode of Anhui's innovative undertaking of high-tech industries transfer: Leading Enterprises + Industrial park to promote the mode of undertaking, differentiated development + Regional comprehensive exploitation of the mode of undertaking and "Dynamic industrial Chain" + industrial cluster mode of undertaking.

This article analyzes the overall innovation situation in Anhui Province, without considering the difference in the level of economic development and the difference in the level of innovation among various prefecture-level cities in Anhui Province. To this end, it is hoped that future studies will be detailed to the in-depth analysis of high-tech industries in various prefecture-level cities and test the value of the theory. It is also possible to expand the research scope to the exploration of high-tech industries in different regions of the country and explore more universal laws.

\section{References}

Dai, C., \& Lu, K. (2017). Analysis and Countermeasures of the Transfer of Electronic Information Industry in Chongqing City. Modern Economic Information, 2, 483-484.

Deng, L. (2012). Research on the mode of undertaking industrial transfer based on the view of ecological civilization. Jilin University Journal Social Sciences Edition, 17(5), 106-111.

Gu, L., \& Zou, Y. (2015). Innovation of Undertaking Industrial Transfer in Chengdu-Chongqing Economic Zone from the Perspective of Industrial Upgrading and Spatial Equilibrium. Inquiry into Economic Issues, 5, 123-130

Hwang, K. (2003). In Search of a New Paradigm for Culture Psychology. Asian Journal of Social Psychology, 6(3), 287-291.

Jiang, F., \& Luo, X. (2016). An Analysis of Cooperation and Co-construction Models of Industrial Parks: A Case Study of Jiangsu Province. Urban Problems, 7, 91-96. 
Klmienko, M. (2003). Competition, Matching, and Geographical Clustering at Early Stages of the Industry Life Cycle. Journal of Economics and Business, 56(3), 177-195.

Li, M., Cui, F., \& Deng, X. (2016). Analysis of the Impact of Domestic Demand and Foreign Demand on FDI Location Selection - Based on the Perspective of New Economic Geography. Journal of International Economic Cooperation, 2, 49-54.

Sammarra, A., \& Belussi, F. (2006). Evolution and Relocation in Fashion-led Italian Districts: Evidence from Two Case-studies. Entrepreneurship \& Regional Development, 18(6), 543-562.

Wang, B., \& Zhu, H. (2017). Research on patterns and problems of industry acceptance in central and western regions based on the perspective of industrial chain integration. Economic \& Trade, 2, 284.

Wang, J. (2010). What are the factors directly promoting the transfer of industries between domestic regions?. Academic Research, 11, 46-51.

Wang, F. (2016). The Development Process and Trend of China's High-tech Industry Policy -Based on the Research of High-tech Industry Policy Since 1949. Research on Development, 25(1), 129-136.

Wang, H., \& Huang, Z. (2016). Study on the Problems of Innovation and Industry Transfer Mode in Lanbai Economic Zone. Productivity Research, 11(1), 45-49.

Wang, R., \& Ma, D. (2016). Research on the Efficiency of Green Innovation in Central China under the Background of Industrial Transfer. Enterprise Economy, 27(3), 144-150.

Wang, T., \& Wang, X. (2013). Depth docking mode selection of high-tech industry in Fujian and Taiwan - based on QSPM matrix analysis. Asia-pacific Economic Review, 13(1), 135-142.

Yang, G., \& Pan, J. (2014). The policy of undertaking industrial transfer in the middle and western regions should be turned to. Economic Review, 5, 71-76.
Yang, L., \& Wan, L. (2012). Construction of Industrial Parks: A Study of Industrial Transfer in the Yangtze River Delta under the Constraint of Social Capital. Reform of Economic System, 12(6), 61-65.

Xu, D. (2015). Current China's Interregional Industry Transfer and Its Characteristics: An Analysis Based on Three Dimensions. Urban and Environmental Studies, 3, 67-81.

Yu, L., \& Xiao, L. (2015). A Study on the Evaluation System of High-tech Innovation and Promotion of Traditional Industries - Taking Henan Province as an Example. Science \& Technology Progress and Policy, 32(5), 122-125.

Zeng, G., Zhou, G., \& Guo, Y. (2015). Study on the Effective Acceptance of Changzhu Industrial Transfer in Jiangxi Province under the Perspective of Industrial Agglomeration. Regional Economic Review, 23(1), 123-126.

Zhao, C. (2017). Analysis on Advantages and Disadvantages of Zhangjiakou's Industry Transfer from Beijing to Tianjin. Hebei Finance, 11(9), 44-48.

Zhou, H., Chen, Y., \& Wu, X. (2014). Research on Design Outsourcing International Design Outsourcing in Jiangsu Province. Science and Technology Management Research, 31(18), 157-161.

Zhang, Y. (2015). Research on the Pattern of Industrial Transfer in Southern Hunan. Market Modernization, 23, 139-140.

Zhang, Y., \& Huang, B. (2015). Research on Industrial Acceptance, Innovation Drive and Regional Coordination Development. Reform of Economic System, 6, 62-67.

Zhu, T., \& Zou, S. (2013). Study on the Status Quo and Mode of Industrial Transfer in Central and Western Regions. Journal of Business Economics, 12, 83-91. 